\title{
How to Support (Political) Decisions? Presentation of a Micro-simulation Model to Assess the Implications of EU-wide Tax Reforms
}

\author{
Stefan Hohls ${ }^{1, *}$ \\ ${ }^{1}$ Georg-August-Universität Göttingen, \\ Abteilung für deutsche und internationale Besteuerung, Göttingen \\ Stefan.Hohls@wiwi.uni-goettingen. de
}

\begin{abstract}
Current discussions of possible tax reforms are characterized by an increasing relevance of related governments' budgetary implications, thus, in this respect each tax reform proposal is reviewed in detail and an assessment of the consequences is essential from a political point of view. We developed the innovative micro-simulation model ASSERT (Assessing the Effects of Reforms in Taxation), which factors in changes in macro-economic conditions (GDP growth) as well as cross-border effects to analyze EU-wide tax reforms. To this end ASSERT is based on firm-level data, applies a forecasting algorithm and considers tax provisions for European countries. This paper presents the current version of the artifact as well as the development/evaluation process.
\end{abstract}

Keywords: Taxation Revenue Model, ASSERT, DSR, Simulation.

\section{Introduction}

In the recent past, a number of EU member states reformed their provisions governing company taxation. The German government, for example, changed the Corporate Tax Act in 2008 by drastically reducing the tax rate and adjusting other regulations in order to ensure Germany's tax revenue in the long term by preventing extensive profit shifting to other European or foreign countries [13]. The European Commission proposed the Common Consolidated Corporate Tax Base (CCCTB), an alternative EU-wide tax regime, in 2011 [7].

Against the background of the currently constraint governments' budgetary situation, which can be observed in many member states as a consequence of the recent financial and global economy crisis, each reform scenario has to be discussed, evaluated and reviewed in detail. Whereas the effects for small or stand-alone corporations can be assessed reviewed relatively easily, the evaluation for larger corporations and corporate groups, especially in an international context, has proven to be difficult. Those cases are characterized by complex cause-effect relationships and cannot be

\footnotetext{
The micro-simulation model ASSERT has been developed by Andreas Oestreicher, Reinald Koch, Dorothea Vorndamme and Stefan Hohls, Georg-August-Universität Göttingen.
} 
determined manually, particularly if a reform proposal is to be evaluated from a political point of view. Complexity is further increased if changes in the macro-economic changes are taken into account.

To this end, we developed the micro-simulation model ASSERT, acronym for Assessing the Effects of Reforms in Taxation, which enables an assessment of the impact of alternative tax regimes for stand-alone companies and corporate groups (considering national as well as international relations) in the EU on tax revenue. In doing so, national tax reforms can be evaluate taking account of effects resulting from (inter-) national company relations as well as the CCCTB reform proposal. Factors determining future company development are applied by using a forecasting method, which is, to our knowledge, a novelty in this context.

We identified four main modeling challenges. Since micro-simulation models are based on firm-level data and the data source provides firm-level data for European companies in a standardized format allowing for a relatively low degree of detail, there is a need to generate more detailed data to apply tax provisions (1). In order to reflect changes in the general economic environment, a forecast routine of the companies' future development is essential (2). We need to include companies' behavior and interactions between companies in the model. This is done by anticipating, in the present version, ex ante companies' decision making with regard to making use of an available group taxation system or companies' financing (3). Strategic company decisions (e.g. location decisions) are explicitly not addressed. Finally, the tax provisions need to be modeled for all European countries as detailed as necessary and as standardized as possible (4).

The remainder of the paper is structured as follows: In Section 2 the related work concerning tax revenue models and Design Science Research is presented. The artifact development, with a special focus on necessary data and routines for forecasting companies' development, is the subject of Section 3. Subsequently, according to Design Science Research, the developed artifact are evaluated. Finally, Section 5 gives a conclusion and an outlook for further research.

\section{Related Work}

Based on the necessary input data as well as the accuracy, existing artifacts can be classified into macro-economic models and models, which process individual (micro-)data [22]. Although macro-economic models allow for the consideration of taxes, micro-simulation models are more suitable for assessing implications induced by tax reforms, because of the opportunity to explicitly process individuals' characteristics as well as more detailed tax-provisions [5,16,24]. Within micro-simulation models, two types of models can be distinguished [16]. Static micro-simulation models determine the tax liability by applying relevant tax provisions as detailed as possible to accounting data realized in the past. The simulation is processed both for the current tax regime and the respective reform proposal. By comparison of the simulated tax revenues, the different tax regimes can be evaluated. Existing micro-simulation models designed for the purpose of tax policy evaluation usually follow this approach. 
The DIECOFIS model [20] is a one-period model and was applied for an analysis of an Italian tax reform. The German model BizTax [2] and the German TaxCoMM model [24] apply a static micro-simulation approach and quantified the impacts resulting from the German tax reform 2008 [1,9]. The above mentioned models are limited to a single country. Koch [15] quantifies the effects of alternative tax regimes (CCCTB) by applying an EU-wide static simulation model.

The static simulation approach avoids any estimation error involved with a forecasting algorithm. However, the results are only valid, if the determining factors are still applicable [16]. Contrastingly, dynamic micro-simulation models (as ASSERT) rely on forecast algorithms and are, thus, able to take account of changes in the macro-economic conditions, examples are the recent economic and financial crises. Dynamic micro-simulation models are not suitable to predict macro-economic effects but rather are based on macro-economic models in order to regard changes in macroeconomic conditions, for example GDP growth. Although three approaches have been developed in the literature for forecasting (taxable) income [3-11] in a different context, dynamic simulation models are still absent.

The evaluation of tax reforms cannot be handled manually, thus, "Information Systems are implemented [...] for the purpose of improving the effectiveness and efficiency" [12]. In order to support the (political) decisions in an effective and efficient manner, artifacts are developed using design science [17]. For design science research, guidelines as well as process schemes are provided for developing and evaluating artifacts [12,21]. Besides, providing an artifact for a solution of an unsolved problem in a certain "problem domain" (usefulness), the design science research focuses on the development processes as well as the presentation of the insights [12].

The relation between the problem and the solution as well as development and evaluation process can be clarified by a paradigm. The "Problem Entity" represents corporations, corporations' behavior and governments' regulations which are elements of the reality. By modeling the reality a "Conceptual Model" is set up which is transferred by implementation and computer programming to a "Computerized Model", the instantiation. To obtain valid results, the processed data needs to be valid. Furthermore the "Conceptual Model" and the "Computerized Model" have to be reviewed, validated and updated if required [25].

\section{Artifact Development}

\subsection{Tax Revenue Model}

The governments' tax revenue (dependent variable) is determined in accordance with equation (1) as the extrapolated total of all companies' tax liabilities per country [19].

$$
\operatorname{TaxRev}_{t}=\sum_{\mathrm{c} \in \mathrm{country}} \operatorname{Tax}_{i_{c} ; t}
$$

The companies' tax liability is defined by companies' taxable income (taxable income consists of earnings before interest, taxes and depreciation (EBITDA); extraordinary income (epl); depreciation (depr); financial income (fpl); received dividends (div ${ }^{\text {rec }}$; 
application of group taxation (gt) and loss offset (lcf)) and the statutory tax rate $(\tau)$ as in equation (2) presented.

$$
\operatorname{Tax}_{i_{c} ; t}=\left(e b i t d a_{i ; t}+e p l_{i ; t}-\operatorname{depr}_{i ; t}+f p l_{i, t}-d i v_{i ; t}^{\mathrm{rec}} \pm g t_{i ; t}-l c f_{i ; t}\right) * \tau_{c ; t}
$$

The tax revenue model can be subdivided into five main steps. The companies' development is forecasted on a year-to-year basis. For the purposes of forecasting future companies' development, two sub-sets of data are created. Firstly, for each simulation company additional information, such as company specific interest rates, net investment, return on assets in year 2007 and probabilities of having an extraordinary income, are calculated. Secondly, we define the historical reference by calculating company specific forecast parameters and creating one referring dataset for each set of three consecutive complete financial statements within the period 2001 to 2006. In order to be able to determine depreciation expenses we need a detailed asset history sheet including the acquisition costs and the respective acquisition dates for different types of assets (machinery, buildings, land, goodwill and patents) [6,19].

In a second step, which is optional and has not been implemented so far, possible behavioral responses could be considered. The derivation of taxable income from forecasted accounting earnings (step three) consists of four sub-processes: dividend exemption, group taxation, inter-period loss offset, determination of final tax liability.

The fiscal treatment of financial income can be characterized as follows: While interest expenses and income are (fully) deductable and taxable, there are no tax consequences with regard to distributed dividends. Underlying profits are fully taxed at the level of the distributing company and, if both companies are incorporated, dividends are tax exempt (except for a lump-sum proportion) at the level of the receiving company (dividend exemption) in accordance with the parent countries' tax law. If companies belong to a tax group, the group's income (sum of EBT after dividend exemption) instead of individual's income is taxed. This may lead to a summing up of positive and negative results, i.e. an intra-group loss offset. If negative income persists also after group taxation, losses are offset across periods according to local tax law before companies' tax liabilities are calculated.

In step four, the liabilities and equity as well as distributed dividends are determined. Based on the companies' tax payments, governments' tax revenue is ascertained by applying an extrapolation routine at the end of the simulation.

\subsection{Dataset Generation}

The main data source is the AMADEUS ${ }^{1}$ database provided by Bureau van Dijk. For each company, general characteristics (e.g., industry, date of incorporation) as well as financial information is provided in a standardized format. For ASSERT, the financial/key data of about four million ${ }^{2}$ private EU companies referring to the period 1994 to 2007 was extracted from AMADEUS and transferred to a three-tier database,

\footnotetext{
Reasons for using AMADEUS database see Poppe (2008).

2 Due to restrictions in the availability of data not all companies included in AMADEUS allowed for further analysis.
} 


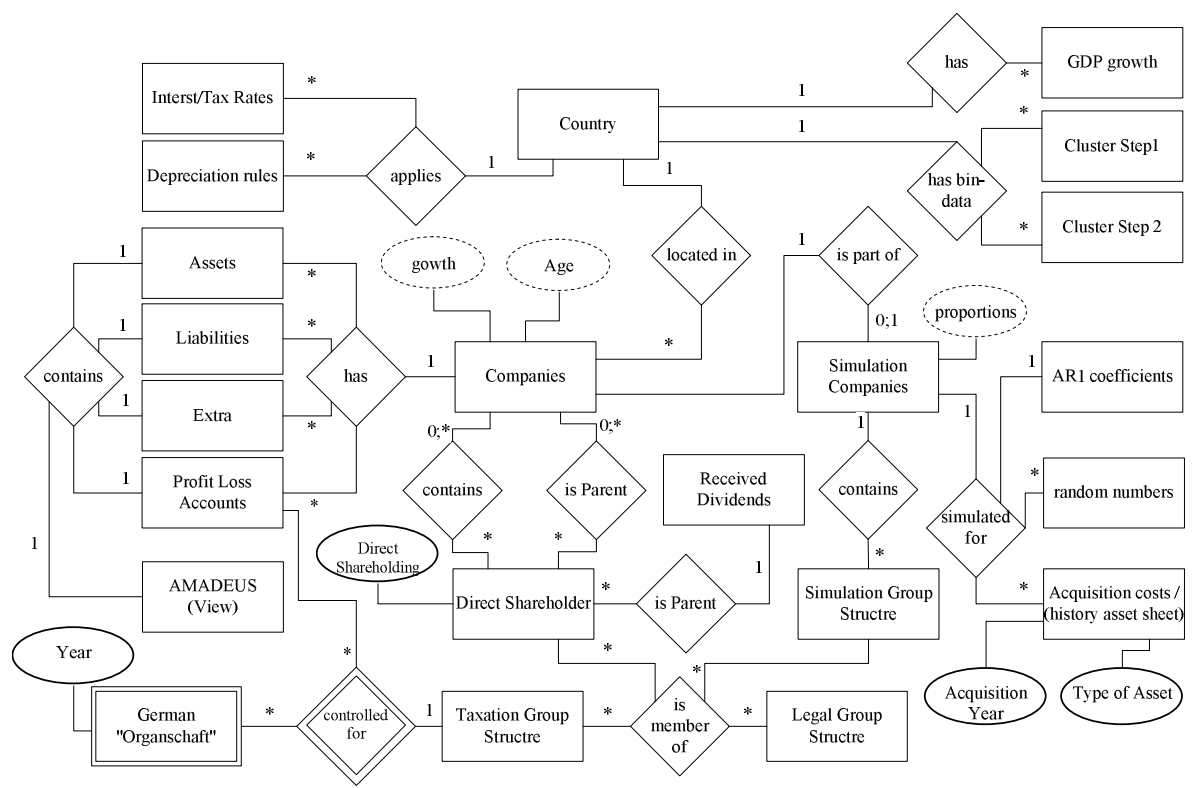

Fig. 1. Illustration of the Dataset Schema

which enables access via SQL, ODBC and JDBC. ${ }^{3}$ Similarly, the ownership information and ratios from other sources was extracted, transformed and loaded as well. The final dataset schema is illustrated by an ER model [4] in Fig. 1.

For the purpose of divide and conquer and tax compliance a determination of three different group structures is required. To this end, we derive a legal group structure, a tax group structure and a process group structure by referring (also indirectly) to the root node of the structure similarly to the transitive closure (Fig. 2) [23].

Regardless of the country setting, (direct and indirect) shareholding of more than $50 \%$ is required for belonging to a legal group. To establish a tax group, the parent company and the subsidiary have to be located in the same country and a specific minimum percentage of (direct and indirect) shareholding, depending on local tax law (greater than $50 \%, 75 \%, 95 \%, 100 \%$ ), is required [18,19]. Finally, all companies that are connected via shareholdings are combined to form one simulation group (Fig. 2), missing simulation companies (company "I") are bypassed and a level-information beginning from the leafs is added. Simulation companies are omitted and, thus, classified as missing companies if they do not provide complete financial statements at least in the years 2006 and 2007 or if they are located in a country for which less than 180 datasets (base-data) having three consecutive entire financial statements can be identified.

3 By courtesy of Bureau van Dijk. 


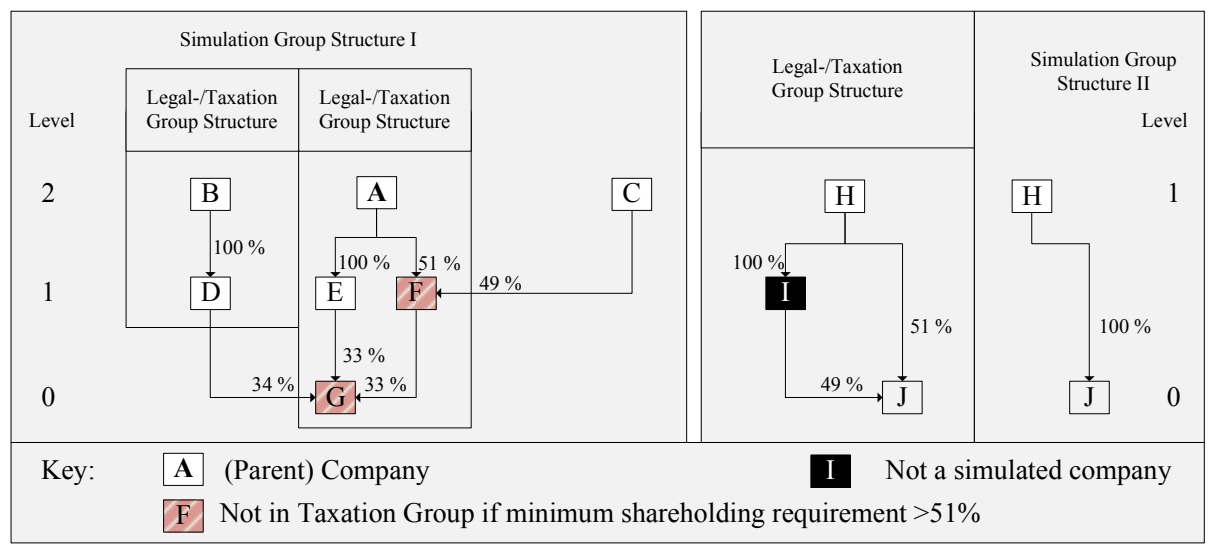

Fig. 2. Legal-/Taxation-/Process- Group Structure

For each country, these datasets (base-data) were clustered in accordance in a first tier with the balance sheet total and in a second tier in accordance with return on assets in a way that each cluster contains approximately the same number of datasets. This procedure results in a number of distinct company bins. Datasets with extreme values in return on assets are excluded. Finally, the mean and median of the bucket attributes are calculated. These values form the basis for simulating future company development (see Section 3.3 for further details).

AMADEUS, however, provides information with regard to the aggregated book values of intangible tangible fixed assets as well as total depreciation. In order to derive an asset history sheet, we indentified the OSIRIS database (also provided by Bureau van Dijk) as the best possible source of additional information on the type of assets. To create an initial asset type structure, we determined country and industry specific ratio from OSIRIS, whereas the initial age structure of assets is derived based on a simple aging algorithm. To this end, the company is accompanied by the purchase of a set of assets, which is replaced in accordance with the amount of economic depreciation (independent from country settings) whereas capital-widening investments are assumed to be realized equivalent to a company-specific average growth factor. After combining these initial asset type and age structures, a simulated amount of depreciation is derived and compared with the actual depreciation as reported in AMADEUS, which represents a benchmark for the simulation routine. To approximate the actual depreciations, an iterative numerical algorithm (maximum 10,000 iterations) was developed. Since we have two dimensions, we adjust both the asset type structure by shifting the proportions as well as the age structure by shifting to newer or older acquisition dates in each iteration [19]. The determination of the asset history sheet is illustrated by Fig. 3 . 


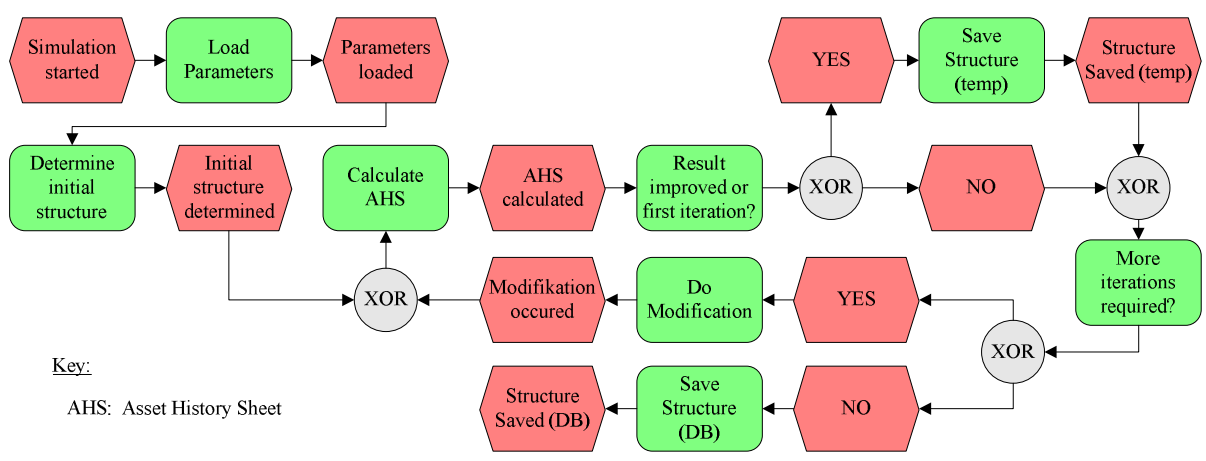

Fig. 3. Visualization of determine asset history sheet

\subsection{IT-Artifact Instantiation}

The dataset generation and the tax revenue model described in the previous sections are realized by a number of IT-Artifact Instantiations.

The routines creating the detailed asset and financial information is carried out in JAVA. All needed country settings and company information are loaded from the database via JDBC and are organized in country and company objects. For accessing the data getter-methods are used. In order to reuse code-fragments and to alleviate verification of the results for each main calculation step, a sub-procedure is created. Information that is taken out of our database is processed by SQL functions. External analysis is done in STATA. The required data as well as the results are transmitted via ODBC. For clustering the data, Oracle's NTILE function is used.

Whereas the first stage of development of the tax revenue model for the simulation years (implementation) was driven by a process view, we set up an integrated system which is implemented in JAVA. To this end, we define a company object, which represents all company attributes (historical as well as simulated characteristics) as the centre of the artifact (Fig. 4).

Depending on the number of companies to be simulated, which is determined by the respective research question, the simulation process might be partitioned according to the simulation group structure. After having imported the country settings and companies' initial attributes, the forecasting is carried out in the Simulation class. To this end, the following items are forecasted: return on assets and thus EBITDA, extraordinary income, sales, operating revenue turnover, employees and costs of employees, depreciation and amortization, investments, current assets, other fixed assets (financial assets), financial revenue and at the end EBT (earnings before taxes). The forecast of these items follows, if not otherwise stated, the bin-approach. This simulation procedure refers to the development of similar companies (see Section 3.2 for the determination of the bins of similar companies) and generally follows equations (3) and (4).

$$
\text { attribute }_{t}=\text { attribute }_{t-1} *\left(1+\text { attribute }_{\text {bin }}\right)
$$




$$
\text { attribute } \left._{\text {bin }}=\text { Median }_{\left(\frac{\text { attribute }_{t}}{\text { attribute }_{t}+\text { attribute }_{t-1}}\right.}^{2}\right)
$$

More specifically, the forecast of the return on assets is realized by a Monte-Carlo simulation and follows the bin-approach exclusively only if the companies' development is not sensitive to the GDP growth. In all other cases, the bin-approach is combined with an AR1 approach which relies on company individual coefficients.

The forecast of extraordinary income applies two distinct steps. Firstly, a uniformly distributed random variable, corresponding to the companies' past, points to whether an extraordinary income is to be simulated or whether extraordinary income is zero. The second step determines, if necessary, the amount of extraordinary income by way of a Monte-Carlo simulation based on the bin-approach. Other company attributes (sales, operating revenue turnover, employees, costs of employees and investments) are forecasted by the bin-approach. Where applicable, investments are simulated in consideration of a GDP growth modification. After depreciation and amortization expenses have been calculated by applying national depreciation rules to the derived asset history sheet, we assign the simulated investments (positive and negative) to each asset to get an updated asset history sheet as well as a forecast for the value of non-financial assets. Other fixed assets and current assets are assumed to grow in accordance with a general company-specific growth factor. Financial revenue is derived from other fixed assets by applying the company specific interest rate which is modified in some cases by a necessary add-on. At the end of the forecasting process we calculate the EBT by summing up the simulated earnings (simulated return on assets multiplied by mean-year's assets), interest and (to avoid a circular reference) previous year's dividends. This module is, with the exception of depreciation and amortization, independent from national tax law.

Tax provisions (step three) are incorporated in the following modules: Firstly, we reduce EBT with the amount of tax exempt (received) dividends, which are treated in accordance with the parent countries' tax law, under consideration of the direct percentage of shareholding and the location of the distributing company (home versus foreign country). The current version of ASSERT implements the exemption rules and the subtraction routine in country specific sub-classes. The procedures for alternative group taxation systems are located in the Group Taxation class and are executed after the dividend exemption. If negative income persists also after group taxation, losses are offset across periods according to local tax law before companies' tax liabilities are calculated. While local loss-offset rules are completely held available in subclasses, the logic is implemented for most of the countries in the upper-class. Only for Austria and Poland the logic is implemented in country sub-classes since in theses countries differing provisions are applicable.

In the last step of the annual simulation, we determine beginning from leafs of the simulation structure iteratively the appropriation of net income (taking account of received dividends from previous iterations) by calculating the distributed dividends as well as the liabilities and shareholders' equity.

In order to make a point to tax reform proposals, we estimate governments' tax revenue by extrapolating the companies' tax by comparing the simulation sample to 


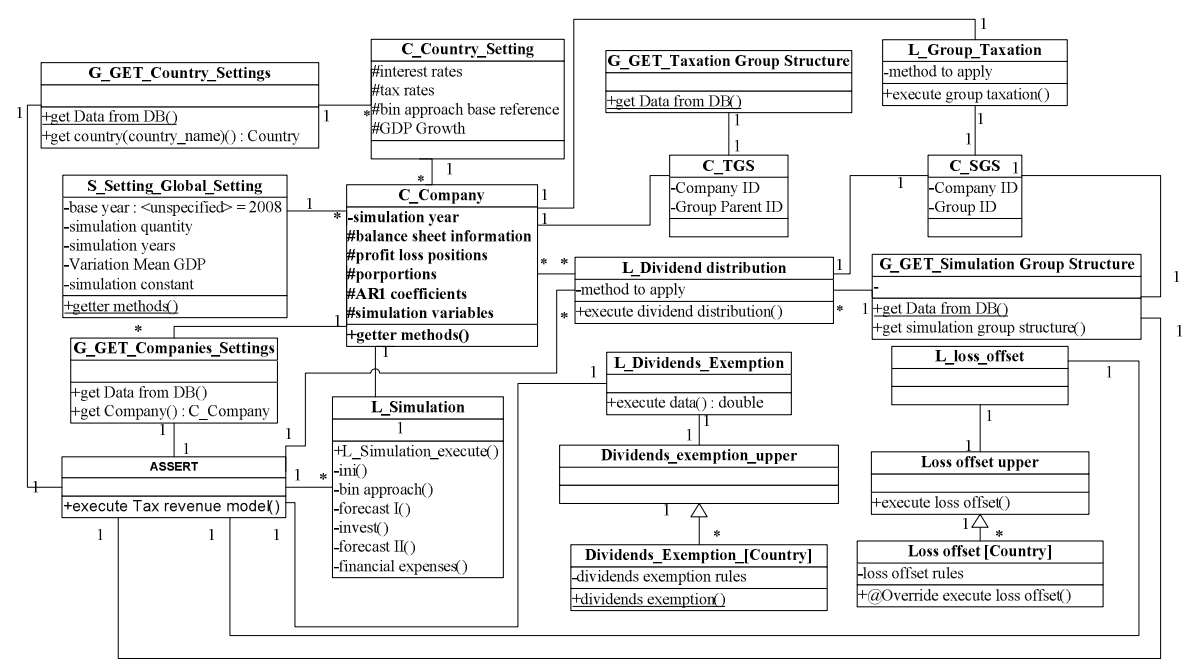

Fig. 4. Illustration of the ASSERT model in UML

the overall population. Companies having negative income are underrepresented in the AMADEUS database compared to the corporate tax statistic. The extrapolation is therefore processed separately for profitable and loss-making companies.

\section{$4 \quad$ Artifact Evaluation}

For the purpose of usefully support decisions, correctness, completeness and reliability are essential preconditions for the basis of assessment. These required characteristics are for ASSERT proven by way of an evaluation guided by Sargent's paradigm both with respect to the overall model and each sub model.

For all elements of data a consistency check was performed. Detailed information on the conditions and number of adaptations are reported in [19]. The validity of the constructed group structures was ascertained by test structures and by way of a caseby-case review.

For the implementation of the asset history sheet, the business needs were transferred to hierarchically structured, event-driven Process Chains (ECP) (overall layer see Fig. 2), which were also used in combination with code-reviewing for verification. During the implementation, all interim stages were observed and the procedure was audited by output statements. Finally, the results were audited in terms of mathematical and logical correctness in accordance with equations (5) and (6).

$$
\begin{gathered}
\text { Book value }_{\text {Dataset }}=\sum_{\text {Asset Type }} \sum_{t} \text { Historical acquisition } \text { costs }_{t} * \text { ratio }_{t} \\
\text { Depreciation }_{\text {Dataset }}=\sum_{\text {AssetType }} \text { Depreciation } \text { simulated }
\end{gathered}
$$

Secondly, we evaluated the accurateness by comparing the simulated book value structure to a survey provided by the German Central Bank (GCB). It becomes 
apparent that the simulated structure for tangible fixed assets provides a good approximation of the structures reported by the GCB, whereas the applied routine tends to overweigh goodwill with regard to the structure of intangibles. ${ }^{4}$ Finally, we compare depreciation expenses simulated for future years (2008 to 2010) with those actually realized and find a high correlation (more than $90 \%$ ).

Also each part of the Tax Revenue Model has been evaluated in separated steps. Essential for the performance of the forecast is that the mapping to relevant bucket is processed as fast as possible. For this purpose the Binary Search Algorithm is implemented. As the requested key is continuous, the company's attribute is allocated to the bin for which the difference between the requested key (company's attribute) and the bin's key is minimal. We added output statements for verifying which path is chosen in order to test for the performance and the correctness of the applied mechanism. Based on the mapping, the companies' forecasted attributes were checked for plausibility. In the first implementation we mapped the requested key by reference to a responding range from minimum to maximum value in the buckets and it was conspicuous that the mapping tend to extreme buckets with the result that the mapping refers now to the median of the bucket values. The correctness has been demonstrated in connection with realized attributes for the period 2008 to 2010. In this respect, we noticed that the effect of forecasted return on assets was overestimated if the bins' return on assets is close to zero. To avoid this error, we adjusted the models and applied an additive forecast of companies' return on assets in that case. By performing white-box tests for extraordinary income forecasted in accordance with a preliminary approach, we noticed that in some cases a value different from zero was predicted although companies' extraordinary income in the past was constantly zero. To avoid this inconsistency, we updated the Conceptual and Computerized models and set up the two-tiered process described in Section 3.3.

For all tax provisions the implementation has been checked for correctness and results-oriented tests have been accomplished. To give an example, in countries where a group taxation system is applied, taxation is based on totaled profits and losses within the tax group. Application of the group tax regime has to ensure that the sum of taxable income remains unchanged while the amounts of both positive and negative taxable income decreases. The fulfillment of these two conditions has been audited as a result-oriented test. In addition, the correctness of the applied procedure has also been checked manually for a random sample of companies.

With regard to the offset of profits and losses over time, the offset procedure (offset limitation and provision changes in time) was tested by way of a case-by-case review. In addition, the sum of the taxable income needs to decrease if losses are offset, whereas the loss carry-forward needs to increase by the same amount. Negative taxable income is permitted only in the case of a carry-back option. Also these conditions were audited by way of a result-oriented test.

4 Since $\frac{\text { Intangible Fixed Assets }}{\text { Total Asset }}=2 \%$ in average, we proceed on the assumption that the effect is minimal. 
Finally, for Germany a black-box validation of the overall model was processed within the scope of a research project. It was shown that the simulated tax revenue are close by the real German tax revenue [18].

\section{Conclusion and Outlook}

The aim of this paper was to present the innovative micro-simulation model ASSERT. According to the Design Science Research Guidelines, we created an artifact in form of a model and an instantiation. The goal of ASSERT, to evaluate the implications of various tax reforms within the EU, was achieved by assessing the effects of an alternative group taxation system in Germany [18]. The strength of this approach is the consideration of changes in the environmental conditions by using a forecasting algorithm. Also cross-border relationships between corporations are considered. The development of ASSERT is based on an iterative solution search process by creating the Conceptual Model and Computerized Model which was permanently evaluated. Since we use individual company data in an aggregated form, we generated more detailed data for the specific purposes of ASSERT by means of assumptions derived from business principles. Starting from a functional implementation by applying the forecast mechanism and the current tax provisions process wise, nowadays the focus is on the company. Therefore we set up an object oriented construct whereby all companies' attributes are available for access at any time.

For the future, an extension of ASSERT is intended. The analysis at the moment is limited to assessing effects of direct consequences resulting from changes in the tax regime (first round effects). Companies' behavioral adoptions (second round effects) are planned as well as a more detailed consideration of special country taxation rules as for instance the German Thin Capitalization Rule.

Acknowledgements. The micro-simulation model has been developed by Andreas Oestreicher, Reinald Koch, Dorothea Vorndamme and Stefan Hohls, Georg-AugustUniversität Göttingen. I would like to say 'thank you' to the project team for the productive work and the crazy time as well as to Jan Muntermann who gave valuable words of advice.

\section{References}

1. Bach, S., Buslei, H., Dwenger, N., Fossen, F.: Aufkommens- und Verteilungseffekte der Unternehmensteuerreform 2008: eine Analyse mit dem UnternehmensteuerMikrosimulationsmodell BizTax. Vierteljahrshefte zur Wirtschaftsforschung / Quarterly Journal of Economic Research 76(2), 74-85 (2007)

2. Bach, S., Buslei, H., Dwenger, N., Fossen, F.: Dokumentation des Mikrosimulationsmodells BizTax zur Unternehmensbesteuerung in Deutschland. Data Documentation 29 (2008)

3. Blouin, J., Core, J.E., Guay, W.: Have the tax benefits of debt been overestimated? Journal of Financial Economics 98(2), 195-213 (2010) 
4. Chen, P.P.-S.: The entity-relationship model—-toward a unified view of data. ACM Trans. Database Syst. 1(1), 9-36 (1976)

5. Creedy, J.: Tax Modelling. The Economic Record 77(237), 189-202 (2001)

6. Devereux, M.P., Griffith, R.: The taxation of discrete investment choices. Inst. for Fiscal Studies, London (1998)

7. European Commision: Proposal for a COUNCIL DIRECTIVE on a Common Consolidated Corporate Tax Base (CCCTB) COM(2011) 121/4 (2011)

8. Fama, E.F., French, K.R.: Forecasting Profitability and Earnings. The Journal of Business 73(2), 161-175 (2000)

9. Finke, K., Heckemeyer, J.H., Reister, T., Spengel, C.: Impact of Tax Rate Cut Cum Base Broadening Reforms on Heterogeneous Firms - Learning from the German Tax Reform 2008 (Working Papers, 1005) (2010)

10. Graham, J.R.: Proxies for the corporate marginal tax rate. Journal of Financial Economics 42(2), 187-221 (1996)

11. Graham, J.R., Kim, H.: Simulating Corporate Marginal Income Tax Rates and Implications for Corporate Debt Policy (2009)

12. Hevner, A.R., March, S.T., Park, J., Ram, S.: Design science in information systems research. MIS Quarterly 28(1), 75-105 (2004)

13. Homburg, S.: Germany's Company Tax Reform Act of 2008. FinanzArchiv: Public Finance Analysis 63(4), 591-612 (2007)

14. Kesti, J.: European tax handbook 2007, 18th edn. International Bureau of Fiscal Documentation, Amsterdam (2007)

15. Koch, R.: Die Aufkommens- und Belastungswirkungen alternativer Vorschläge zur Reform der Konzernbesteuerung in Europa. Lang, Frankfurt am Main (2010)

16. Koch, R.:: Die Bedeutung der steuerlichen Verlustverrechnung für das Steueraufkommen und das Investitionsverhalten. In: Tagungsband zur Veranstaltung "Aktuelle Fragen der Unternehmensbesteuerung" (2012) (forthcoming)

17. March, S.T., Smith, G.F.: Design and natural science research on information technology. Decision Support Systems 15(4), 251-266 (1995)

18. Oestreicher, A., Koch, R., Vorndamme, D., Hohls, S.: Aufkommenswirkungen einer Abschaffung des Ergebnisabführungsvertrags bei der ertragsteuerlichen Organschaft. Inst. Finanzen und Steuern, Berlin (2012)

19. Oestreicher, A., Koch, R., Vorndamme, D., Hohls, S.: ASSERT - Assessing the Effects of Reforms in Taxation. A Micro-simulation Approach, Working Papers (2011)

20. Oropallo, F., Parisi, V.: Will Italy' s Tax Reform Reduce The Corporate Tax Burden? A Microsimulation Analysis (Departmental Working Papers, 403) (2005)

21. Peffers, K., Tuunanen, T., Gengler, C., Rossi, M., Hui, W., Virtanen, V., Bragge, J.: The Design Science Research Process: A Model for Producing and Presenting Information Systems Research (2006)

22. Peichl, A.: Die Evaluation von Steuerreformen durch Simulationsmodelle (FiFo-CPE Discussion Papers - Finanzwissenschaftliche Diskussionsbeiträge, 05-1) (2005)

23. Poppe, A.: Auswirkungen der Einführung einer konsolidierten KörperschaftsteuerBemessungsgrundlage in der Europäischen Union. Eine empirische Analyse der Konzernstrukturen und des Steueraufkommens. Lang, Frankfurt am Main (2008)

24. Reister, T., Spengel, C., Finke, K., Heckemeyer, J.H.: ZEW Corporate Taxation Microsimulation Model (ZEW TaxCoMM) (ZEW Discussion Papers, 08-117) (2008)

25. Sargent, R.G.: Verification and validation of simulation models. In: Proceedings of the 37th Winter Simulation Conference, Orlando, FL, USA, December 4-7, pp. 130-143. ACM (2005) 